\title{
An Economic Analysis on the Viability of Harnessing Wind Energy for Power Generation in Kaduna State, Nigeria
}

\author{
Onwumere Michael ${ }^{1}$, Dogara Matoh Dary ${ }^{1,}$, Aboh Hycinth $^{1}$, Gyuk Philip ${ }^{1}$, Akutson Seth ${ }^{2}$, \\ Akuso Jonah ${ }^{2}$ \\ ${ }^{1}$ Department of Physics, Kaduna State University, Kaduna, Nigeria \\ ${ }^{2}$ Department of Economics, Kaduna State University, Kaduna, Nigeria
}

Email address:

dogaramatoh@yahoo.com (D. M. Dary)

${ }^{*}$ Corresponding author

\section{To cite this article:}

Onwumere Michael, Dogara Matoh Dary, Aboh Hycinth, Gyuk Philip, Akutson Seth, Akuso Jonah. An Economic Analysis on the Viability of Harnessing Wind Energy for Power Generation in Kaduna State, Nigeria. Science Journal of Energy Engineering.

Vol. 5, No. 5, 2017, pp. 124-129. doi: 10.11648/j.sjee.20170505.12

Received: April 7, 2017; Accepted: April 20,2017; Published: November 8, 2017

\begin{abstract}
This paper presents an economic analysis on the viability of harnessing wind power for power generation in Kaduna State, based on wind data analysis of Kaduna and Zaria. The available wind power density of both Kaduna and Zaria of $246.69 \mathrm{~W} / \mathrm{m}^{2}$ and $296.76 \mathrm{~W} / \mathrm{m}^{2}$ respectively shows that Kaduna and Zaria can harness wind power for power generation at utility scale. How economical this would be in the long run is what this paper seeks to analyse. The one-time cost of planting a $300 \mathrm{MW}$ capacity wind turbines in either Kaduna or Zaria was found to be $\$ 716,680,000$, which does not include the annual variable costs of $\$ 17,927,750.2$. With the assumption that capital would be loaned from a bank at $7 \%$ interest to pay back in 30 years, the annual capital payment is estimated to be $\$ 57,754,663.67$. Considering capacity factor, line losses, and a total annual costs of $\$ 90,121,079.79$, the average cost of electricity per kWh was estimated as $\$ 0.0909$.
\end{abstract}

Keywords: Economics of Wind Energy, Weibull Distribution and Parameters, Power Density

\section{Introduction}

The underlying question when installing wind turbines at a particular location for wind power generation is, 'is it economically viable?' This is because, the motivation of investors is hardly 'protecting the environment from climate change' but 'making monetary profit'. Therefore, the economic viability of wind power generation of a particular location, is the determining factor as to whether a viabilityresearch would be just another academic treatise to be abandoned on the 'shelf' or whether it would be implemented.

This paper presents an economic analysis of the viability of wind power generation in Kaduna State. It is based on a statistical analysis of wind-speed data obtained from an 11 year period (2004-2014) wind speed data obtained from the Kaduna Meteorological Station and the Zaria Meteorological Station located at the Kaduna Airport, Kaduna and the Nigerian College of Aviation Technology, Zaria respectively.
And on cost analyses of exploiting wind power for power generation in Kaduna State.

\subsection{Location of Study Area and Economic Significance}

Kaduna State is situated on the southern end of the High Plains of North-West Nigeria; and lies close to the centre of Northern Nigeria. It is bordered by the Federal Capital Territory to the South; Katsina, Kano, and Sokoto to the North; Plateau State to the East, and Niger State to the West. Its strategic geographical location and relief makes it a good ground for testing the average capacity or average potential of wind power generation in Northern Nigeria. Also, Kaduna State has a lot of industries such as the Ideal Flour mills, Peugeot Automobile, Berger Paints, Nigerian Textile Industry, and the Northern Nigerian Publishing Company which are highly dependent on electric power; therefore, even if the wind power capacity is just sufficient for powering these industries alone; so that these industries are no more dependent on the national electric grid, this would 
be very helpful for the country-economically. Agriculture constitute the major occupation of the people of Kaduna State; with many of its citizens participating in small scale farming and animal husbandry; therefore, even if the wind power capacity is just sufficient for generating electricity for farms and farm storage facilities, it would also be beneficial to the country-economically, as a lot of farm produce get wasted-year-in-year-out, because of poor electricity supply to storage facilities. The strategic location of Kaduna State, makes it a good place to site a wind power station that can distribute wind power to neighbouring state whose wind speed may not be viable for wind power production [1]

Now, Mando-Kaduna and Paladan-Zaria are only an infinitesimal fraction of Kaduna State. The research is based on the hypothesis that these two locations could represent the possible wind potentials of Kaduna State as a whole. And these locations were chosen only because of their peculiarity for having standard meteorological stations. The research is also based on the trust that documented archival wind speeds data gotten from these meteorological stations of the specified period (2004-2014) are scientifically accurate and reliable.

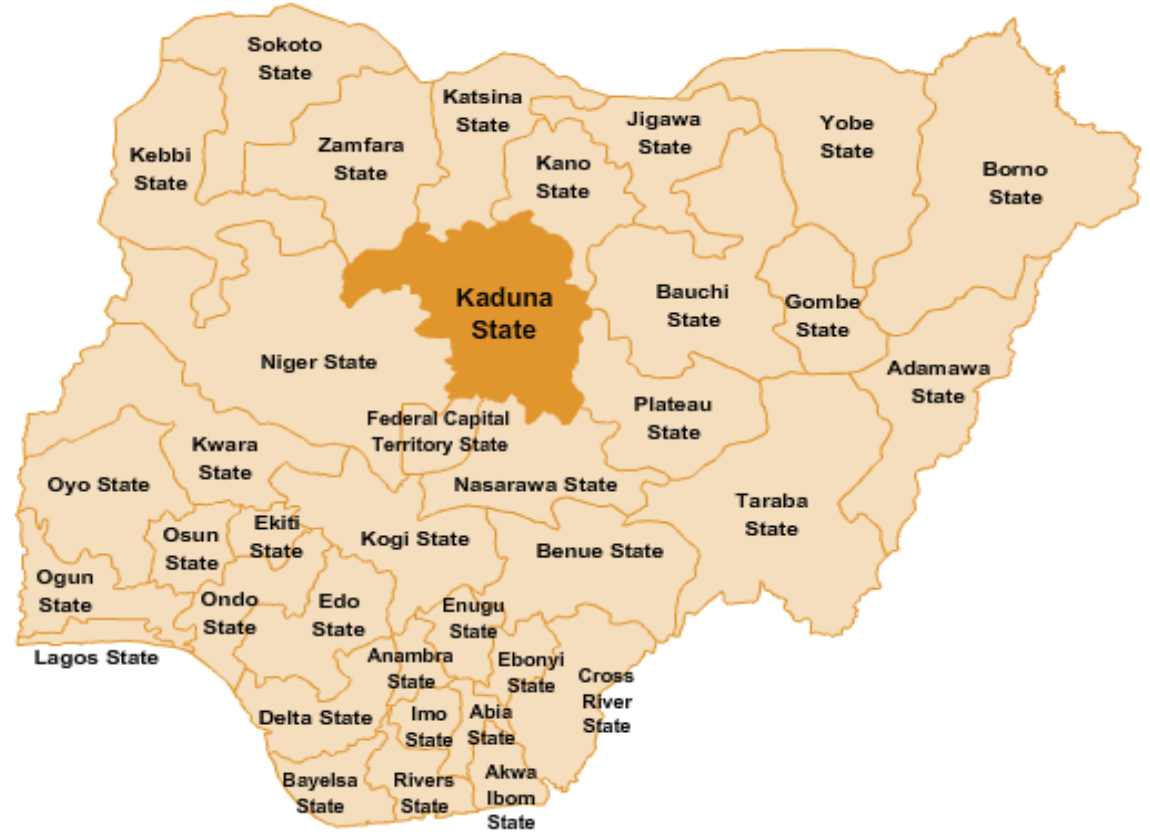

Figure 1. Map of Nigeria showing kaduna state and other neighbouring states.

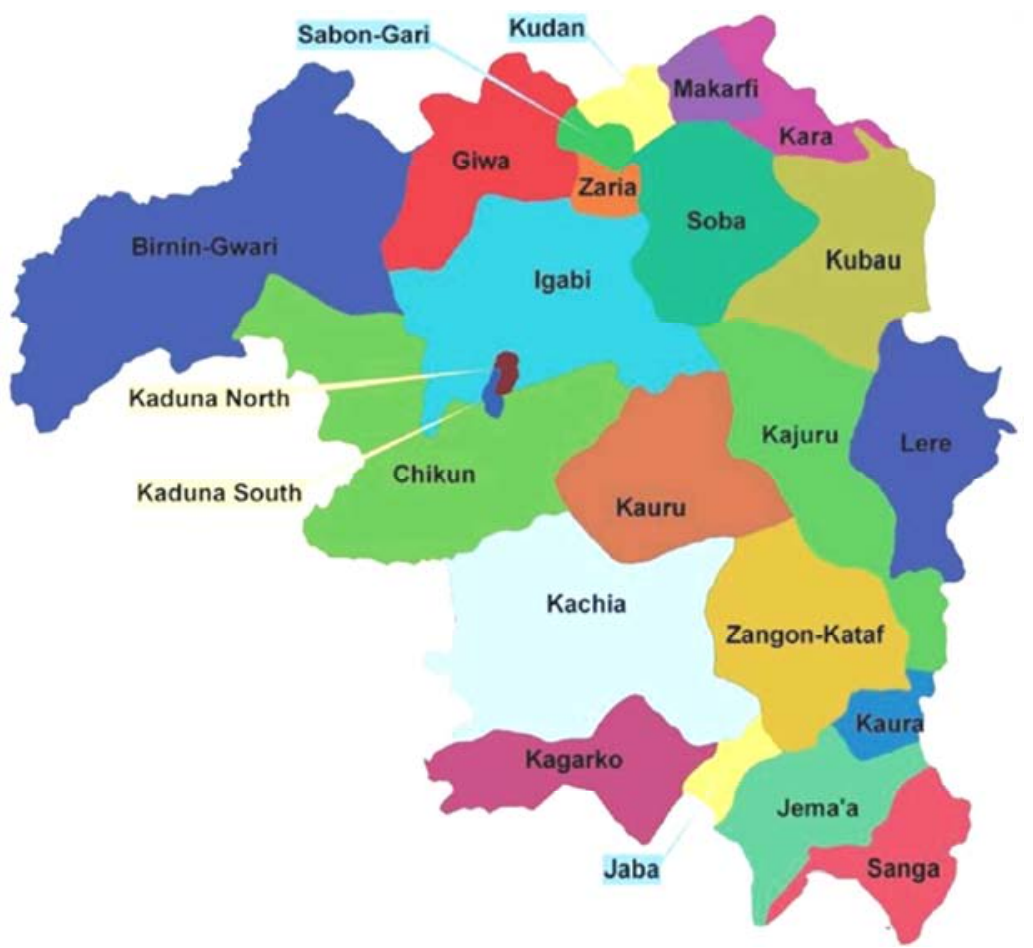

Figure 2. Map of Kaduna state with local government areas. 


\subsection{The Principle of Wind Power Generation}

The principle of wind power generation can be stated as follows, "for all wind turbines, wind power is proportional to wind speed cubed.' Since wind energy is the kinetic energy of moving air [2] The kinetic energy of a mass $m$ with velocity $\mathrm{v}$ is given by

$$
E_{\text {kinetic }}=1 / 2 m v^{2}
$$

The air mass $\mathrm{m}$, can be determined from the air density $\rho$, and the air volume $\mathrm{V}$ according to

$$
m=\rho V
$$

Then,

$$
E_{\text {kinetic }(\text { wind })}=1 / 2 V \rho v^{2}
$$

Since power is energy divided by time, we consider a small time, $\Delta t$, in which the air particles travel a distance $s=v \Delta t$ to flow through. We multiply the distance with the rotor area of the wind turbine, $A$, resulting in a volume of

$$
\Delta V=A v \Delta t
$$

Which drives the wind turbines for the small period of time. Hence, the wind power is given as

$$
\begin{aligned}
P_{\text {wind }} & =\frac{E_{\text {kinetic }(\text { wind })}}{\Delta t} \\
& =\frac{\Delta V \rho v^{2}}{2 \Delta t} \\
& =\frac{\rho A v^{3}}{2}
\end{aligned}
$$

The variations in wind speed, makes the use of wind speed and air density alone, unreliable for analysis of wind power potential [3] Hence, the need of a reliable statistical analysis of wind speed data. The Weibull Distribution Analysis method is adopted for this work; as it has been described by Justus et al [4] and Hennessey [5] as best fit for energy analysis.

\subsection{Weibull Distribution Analysis}

The Weibull distribution is a continuous probability distribution named after the Swedish Engineer, Physicist and Mathematician Waloddi Weibull, who popularized its use for reliability analysis, when he applied it when studying materials in tension and fatigue. Although Weibull's paper on the subject was first published in 1939, the method did not attract much attention, until the 1950's. The Weibull distribution method provides a close approximation to the probability laws of many natural phenomena, and has been used to represent wind speed distribution for application in wind load studies for some time. A lot of attention has been focused on this method for wind energy application in recent years, not only due to its greater flexibility and simplicity but also because it can give a good fit to experimental data [6]

Its Probability Density Function (PDF) is mathematically expressed for wind speed as:

$$
f(v)\left(\frac{k}{c}\right)\left(\frac{v}{c}\right)^{k-1} \exp \left[-\left(\frac{v}{c}\right)^{k}\right]
$$

And its Cumulative Distribution Function (CDF) expressed as:

$$
F(v)=1-\exp \left[-\left(\frac{v}{c}\right)^{k}\right]
$$

Where $v$ is the wind speed, $k$ is the shape parameter and $c$ is the scale parameter. [3]

\section{Wind Data Analysis}

The 11 year period (2004-2014) wind data obtained from the Nigerian Meteorological (NIMET) stations situated on the global coordinates of Longitude- $07^{\circ} 19$ '12" $\mathrm{E}$ and Latitude- $10^{\circ} 41^{\prime} 46^{\prime \prime} \mathrm{N}$, at an Altitude of $632 \mathrm{~m}$ above sea level and Longitude $0741^{\prime} \mathrm{E}$, Latitude $1108^{\prime} \mathrm{N}$, at an Altitude of $686 \mathrm{~m}$ above the sea level, located at the Kaduna Airport, Mando-Kaduna and the Nigerian College of Aviation Technology, Paladan-Zaria, respectively was computed; so that, the monthly mean wind speed $(\bar{v})$ and the average available wind power density $\left(P_{d}\right)$ was obtained using equation (8) and equation (9) respectively.

$$
\begin{gathered}
\bar{v}=(1+1 / \mathrm{k}) \\
P_{d}=\frac{1}{2} \rho \bar{v}^{3} X(P D F)
\end{gathered}
$$

\section{Economic Analysis}

After analysis of wind speed data, the estimated available wind power densities for Kaduna and Zaria were found to be $246.69 \mathrm{~W} / \mathrm{m}^{2}$ and $296.76 \mathrm{~W} / \mathrm{m}^{2}$ respectively. Based on the National Renewable Energy Laboratory (NREL), U.S. Department of Energy (DOE) Wind Power Class Chart (Table 1 below) the available wind power density of Kaduna falls in power class four (4) and that of Zaria falls in power class five (5) which according NREL is sufficient to power utility sized wind turbines.

Table 1. Wind Power Class at $10 \mathrm{~m}$ Elevation Chart [7].

\begin{tabular}{ll}
\hline POWER CLASS & AVAILABLE POWER DENSITY $\left(\mathbf{W} / \mathbf{m}^{2}\right)$ \\
\hline 1 & $0-100$ \\
2 & $101-150$ \\
3 & $151-200$ \\
4 & $201-250$ \\
5 & $251-300$ \\
6 & $301-400$ \\
7 & $401-1000$ \\
\hline
\end{tabular}

In this section, we analyse the cost implication of setting up wind farms in either Kaduna or Zaria. 


\subsection{Cost Analysis}

The cost analysis is based on certain assumptions, with the justifications from authoritative sources. This assumptions include:

\subsubsection{The Location of Wind Farms}

Since wind speed data were sourced from the Kaduna Airport and the College of Aviation Technology, Zaria Meteorological stations for Kaduna and Zaria respectively, we assume locating the wind farms not too far or just a few kilometres away from these stations. As wind speed changes significantly over a large distance.

\subsubsection{The Size and Cost of Wind Farms}

The creation of a wind farm with $300 \mathrm{MW}$ of generation capability each for Kaduna and Zaria was assumed. Making a total of 600MW generation capability for Kaduna State. Since both areas have developable wind resources on this scale. This would require theoretically $2001.5 \mathrm{MW}$ Turbines, each requiring about 90 acres, for a total land requirement of 18,000 acres (or $73 \mathrm{~km}^{2}$ ) for each area [8] 18,000 acres of land each is required theoretically to achieve a generation capacity of $300 \mathrm{MW}$ each. However, installed capital will only occupy a small portion of this land. Turbines, electrical facilities, and service roads average between 0.25 and 0.5 acres per turbine [7]. Therefore, taking the higher of these two estimates, we anticipate each site requires just a 100 acres (about 700 plots of land). The estimated cost of 100 acres of land in Kaduna and Zaria is, \$1 Million.

\subsubsection{Installed Capital Costs}

On May 15, 2008 Mesa Power LLP signed a \$2 Billion with GE in the U.S. to produce $6671.5 \mathrm{MW}$ turbines. The proposed wind farm would therefore have a generating capacity of 1,000 MW, leading to a ratio of $\$ 2$ Million/MW installed capacity. This ratio is higher than many estimates [8] Hence, we assume this ratio and increase it by $19.28 \%$, which is the highest inflation rate in Nigeria from 2007-2017 obtained in January 2007 [9] to get $\$ 2,385,600 / \mathrm{MW}$ (Although, installed capital costs of wind turbines get cheaper with time [10] and Wiser et al [11], predicts $24-30 \%$ reduction in price by 2030 and $35-41 \%$ reduction by 2050 . This rate of cost reduction is neglected to assume the worst case scenario; so that if harnessing wind energy for power generation in Kaduna State proves economically viable in the worst case scenario, then it is very viable)

\subsubsection{Grid Integration Costs}

The variable nature of wind makes it unreliable to be depended upon as a sole source of power generation. Hence, places an extra burden on the grid whenever the wind is not blowing or is not blowing sufficiently strongly. Therefore, integrating wind power with hydro-electric power (as an extra electricity generating capacity) is required. The international Renewable Energy Agency (IRENA) estimates the Grid Integration Costs to range between $15-30 \%$ of Installed Capital costs [12] We assume 30\% of installed capital (the worst case scenario).

\subsubsection{Operation and Maintenance Costs}

Ragheb estimates $1.5 \%$ per year of Installed Capital Costs which is higher than many estimates [10]. We assume paying for a 30 year period.

\subsubsection{Insurance Costs}

Wiser and Kahn's estimated the insurance cost for property insurance, as a percentage $(0.0015 \%)$ of installed capital costs [13] We assume this estimate which is higher than many estimates.

\subsubsection{Capacity Factor}

The capacity factor of a wind farm refers to the percentage theoretical power output, actually produced by the wind farm. This is dependent on a number of variables, which include: the turbine design, where the project is sited, and weather. Hence, it is difficult to predict with a great degree of certainty. The assumption of $41 \%$ put forward by Ryan Wiser and Mark Bolinger of Lawrence Berkeley National Laboratory, [8] was adopted for this work. As it is lower than the Betz limit of $59.3 \%$.

\subsubsection{Transmission Costs}

Mills et al, estimates the transmission costs as $25 \%$ of installed Capital costs this is higher than many estimates. And transmission operation and maintenance was estimated as $4 \%$ of the one-time transmission costs [14] Bahrman estimates line losses at $8 \%$ over the course of the line [15]. We assume this estimates for this work.

\subsubsection{Project Financing}

We assume taking a 30-year payment Bank loan with annual payments and $7 \%$ interest. Which is a worst case scenario project financing source assumed by Xie et al [8]

\subsection{Environmental Effects}

Wind energy would be less harmful than other conventional and alternative energy sources. A wind farm's total fuel cycle emits few pollutants. As a result of these decreased emissions, wind energy non-economic costs (by quantifying its impact on human mortality and morbidity, man-made structures, amenity losses, global warming, crops and ecosystems) are among the lowest when compared with other energy generation [1]

Furthermore, wind farms have fewer impacts on the land than many other energy sources. If a wind farm is dismantled, the land can easily be restored to its natural state [1]

\section{Discussion}

Analysis of wind speed data, found the estimated available wind power densities for Kaduna and Zaria to be 246.69 $\mathrm{W} / \mathrm{m}^{2}$ and $296.76 \mathrm{~W} / \mathrm{m}^{2}$ respectively. Based on the National Renewable Energy Laboratory (NREL), U.S. Department of Energy (DOE) Wind Power Class Chart (Table 1 ) the available wind power density of Kaduna falls in power class four (4) and that of Zaria falls in power class five (5) which according NREL is sufficient to power utility sized wind 
turbines. A cost analysis was therefore carried out to estimate the cost of establishing 300MW wind farm in either Kaduna or Zaria. The average cost of an acre of land in Kaduna and Zaria was $\$ 10,000$. And 100 acres was the estimated size of wind farm needed for the project. The highest of obtainable cost estimates for various wind projects were used as cost estimates for this work, instead of the average cost estimates. This high estimates predict a worst case scenario. The aim was to ascertain whether or not harnessing wind energy for power generation in Kaduna State would be viable in the worst case scenario, as its economic viability in a worst case scenario would imply that it is very economically viable. The highest inflation rate of Nigeria of $19.28 \%$ from 2007-2017 was also used as the inflation rate of Nigeria, instead of the average inflation rate of $10.13 \%$ [9] Cost analysis were also carried out neglecting the fact that wind energy costs decrease with time; hence, neglecting the rate of reduction of wind energy costs put forward by Wiser et al [11] Furthermore, a bank loan at an interest rate of $7 \%$ for a 30 year period put forward Xie et al [8] which is higher than many estimates was assumed to be the source of project financing.

Table 2 shows the Cost Analysis for either Kaduna or Zaria and Table 3 shows the Expected Electricity Generation. The analysis showed that $\$ 0.0909$ was the average cost of electricity per $\mathrm{kWh}$.

Table 2. Cost Analysis for Either Kaduna or Zaria.

\begin{tabular}{ll}
\hline Capital Costs & \\
\hline Wind Farm Cost $(100$ acres $)$ & $\$ 10,000 / \mathrm{acres}=\$ 1,000,000$ \\
Turbine Costs $(300,000 \mathrm{~kW})$ & $\$ 2,385.6 / \mathrm{kW}=\$ 715,680,000$ \\
One-Time Capital Costs & $=\$ 716,680,000$ \\
Annual Capital Payment, 30-year loan & $=\$ 57,754,663.67$ \\
with $7 \%$ interest & \\
Variable Costs & $=\$ 7,166,800 / \mathrm{yr}$ \\
Grid Integration Costs & $=\$ 10,750,200 / \mathrm{yr}$ \\
Operation and Maintenance & $=\$ 10,750.2 / \mathrm{yr}$ \\
Insurance & $=\$ 17,927,750.2$ \\
Total Variable Costs & $=\$ 75,682,413.87$ \\
Total Annual Generation Costs & $=\$ 179,170,000$ \\
Transmission Costs & $=\$ 14,438,665.92$ \\
One Time Transmission Cost & $=\$ 14,438,665.92$ \\
Annual Payment, 30-yr loan with $7 \%$ & $=\$ 90,121,079.79$ \\
interest & \\
Total Annual Transmission Costs & \\
TOTAL ANNUAL COSTS &
\end{tabular}

Table 3. Expected Electricity Generation for Either Kaduna or Zaria.

\begin{tabular}{ll}
\hline Expected Electricity Generation & \\
\hline Generation Capacity & $=300,000 \mathrm{~kW}$ \\
Capacity Factor & $=41 \%$ \\
Line Losses & $=8 \%$ \\
Total Electricity Generation $(\mathrm{kWh} / \mathrm{yr})$ & $=991,281,600$ \\
COST OF ELECTRICITY PER $\mathrm{kWh}=\$ 0.0909$ & \\
\hline
\end{tabular}

\section{Conclusion}

This study analysed the economic viability of harnessing wind energy for power generation in Kaduna State. Analysis were based on archival data obtained from Kaduna and Zaria meteorological stations. Analysis showed that the wind resource of Kaduna and Zaria is suitable for powering utility sized wind turbines. The cost analysis for $300 \mathrm{MW}$ wind farm was carried out, setting out parameters to assume the worst case scenario with justification from authoritative sources. To determine if harnessing wind energy for power generation in the worst case scenario would be profitable. Cost analysis estimated $\$ 0.0909$ to be the cost of electricity per kilowatthour $(\mathrm{kWh})$, which is $49.5 \%$ times lower than the average cost of electricity in Nigeria of $\$ 0.18 / \mathrm{kWh}$ [16] (Value Added Tax (VAT) and Monthly charges excluded). This shows that harnessing wind energy for power generation is very economically viable.

\section{References}

[1] Onwumere, M. K. O. (2016): Exploitation Of Wind Energy for Power Generation in Kaduna State. MSc. Thesis. Kaduna State University.

[2] Ohunakin, O. S. (2010): Energy Utilization and renewable energy source in Nigeria. Journal of Engineering and Applied Science 5 (2), 171-177.

[3] Dogara M. D., Aboh H. O., Gyuk P. M., and Onwumere M. K. O. (2016): The Use Of Energy Pattern Factor (EPF) in Estimating Wind Power Density. World Science Journal.

[4] Justus, C. G., Hargraves, W. R. and Mikhail, A. (1976): Height variation of Wind Speed and Wind Distribution Statistics. Geophys Res Lett, 3, pp.261-4.

[5] Hennessey, J. R. (1977): Some Aspects of Wind Power Statistics. Journal of Applied Meteorology. 16(2), pp. 119-128

[6] Waewsak, J., Chancham, C., Landry, M., and Gagnon, Y (2011): An Analysis of Wind Speed Distribution at Thasala, Nakhon Si Thammarat, Thailand. Journal of Sustainable Energy \& Environment, 2, pp. 51-55.

[7] NREL (National Renewable Energy Laboratory). (2006): Wind Farm Area Calculator, Power Technologies Energy Data Book. Retrieved from: http://www.nrel.gov/analysis/power_ databook/calc_wind.php

[8] Xie, T., Pejnovic, N., Lees, A. F., and Ewing, E. (2008): Wind Energy: A Thorough Examination of Economic Viability. Energy and Energy Policy. University of Chicago. Retrieved from: http://franke.uchicago.edu/bp-energy

[9] Trading Economics (2017): Nigerian Inflation Rate 19962017. Retrieved from $\mathrm{http} / / /$ tradingeconomics.com/nigeria/inflation-cpi

[10] Ragheb, M (2017): Economics of Wind Energy. Retrieved from: http://mragheb.com/economicsofwindenergy.pdf

[11] Wiser, Ryan., Jenni, Karen., Seel, Joachim., Baker, Erin., Hand, Maureen., Lautz, Eric., and Smith, Aaron (2016): Expert Elicitation Survey on Future Wind Energy Costs. Nature Energy Journal 1. 16135(2016)

[12] IRENA (International Renewable Energy Agency) 2015: Renewable Energy Integration in Power Grids. Technology Brief Retrieved from: http://irena.org/DocumentDownloads/Publications/IRENAET SAP_Tech_Brief_Power_Grid_Integration_2015.pdf 
[13] Wiser, Ryan and Edward Kahn 1996. "Alternative Wind Power Ownership Structures: Financing Terms and Project Costs." Retrieved from: http://eetd.lbl.gov/EA/EMP/reports/38921.pdf.

[14] Andrew Mills., Ryan Wiser., and Kelvin Porter (2009): The Cost of Transmission for Wind Energy: A Review of Transmission Planning Studies. Environmental Energy Technologies Division. Retrieved from: http://eetd.lbl.gov/EA/EMP
[15] Bahrman, M. (2006): Economics of Mine-Mouth Generations with HVDC Transmission Relative to Coal Transport. ABB Grid Systems.

[16] OVO Energy (2011): Average Electricity Prices around the World: $\$ / \mathrm{kWh}$ Retrieved from:

https://www.ovoenergy.com/guides/energy-guides/averageelectricity-prices-kwh.html 